\title{
Separation of water from mixtures containing formaldehyde, water, methanol, methylal, and poly(oxymethylene) dimethyl ethers by pervaporation
}

\author{
Niklas Schmitz ${ }^{\mathrm{a}, \mathrm{c}}$, Christian F. Breitkreuz ${ }^{\mathrm{a}, \mathrm{c}}$, Eckhard Ströfer ${ }^{\mathrm{a}, \mathrm{c}}$, \\ Jakob Burger ${ }^{\mathrm{b}, \mathrm{c}, *}$, Hans Hasse ${ }^{\mathrm{a}, \mathrm{c}}$ \\ ${ }^{a}$ University of Kaiserslautern, Laboratory of Engineering Thermodynamics (LTD), \\ Erwin-Schrödinger-Strasse 44, 67663 Kaiserslautern, Germany \\ ${ }^{b}$ Technical University of Munich, Chair of Chemical Process Engineering, Campus \\ Straubing for Biotechnology and Sustainability, Schulgasse 16, 94315 Straubing, Germany \\ ${ }^{c}$ OME Technologies GmbH, Kaiserslautern, Germany
}

\begin{abstract}
In this work, pervaporation experiments were carried out, in which water was separated from mixtures containing formaldehyde, water, methanol, methylal, and poly(oxymethylene) dimethyl ethers (OME). This separation is interesting for new production processes for the synthetic fuel OME. Five commercial membranes were studied: two zeolite membranes (Type NaA and Type $\mathrm{T}$ from Mitsui \& Co.) and three PVA-based polymer membranes (PERVAP 4100, PERVAP 4101, and PERVAP 4102 from DeltaMem AG). The membrane flux and the composition of the permeate have been measured. The zeolite membranes were tested at $343 \mathrm{~K}$ and 7 mbar permeate pressure and the polymer membranes were tested at $353 \mathrm{~K}$ and 2 mbar permeate pressure. The investigated mixtures are inherently reactive, as formaldehyde reacts both with water and methanol. The zeolite membranes could
\end{abstract}

\footnotetext{
${ }^{*}$ Corresponding author:

Email address: burger@tum.de (Jakob Burger)
} 
only be used once, whereas the polymer membranes showed no significant degradation in a repeat experiment.

\section{Highlights:}

- Poly(oxymethylene) dimethyl ethers (OME) are interesting environmentallybenign synthetic fuels.

- Separation of water from reactive multicomponent mixtures containing formaldehyde, water, methanol, methylal and OME by pervaporation is feasible.

- Membrane fluxes and composition of the permeate are reported for ceramic membranes, Type NaA and Type $\mathrm{T}$, and polymeric membranes PERVAP 4100, PERVAP 4101, and PERVAP 4102.

- Polymeric membranes PERVAP 4100, PERVAP 4101, and PERVAP 4102 are stable in a repeat measurement.

Keywords: Poly(oxymethylene) dimethyl ethers (OME), Separation of water, Pervaporation, Formaldehyde, Methanol

\section{Introduction}

Poly(oxymethylene) dimethyl ethers (OME) are attractive oxygenated diesel fuels [1-4]. The chemical structure of OME is $\mathrm{H}_{3} \mathrm{C}-\mathrm{O}-\left(\mathrm{CH}_{2} \mathrm{O}\right)_{n}-\mathrm{CH}_{3}$ with $n \geq 2$. The desired chain length when using OME as fuels (either pure or in mixtures with conventional diesel fuel) is $n=3-5[1,2]$. When used as diesel fuel, OME drastically reduce the soot emissions. Thus, by burning OME instead of diesel, the well known trade-off between soot and 
$\mathrm{NO} x$ emissions in engines can be circumvented leading also to an indirect reduction of the $\mathrm{NO} x$ emissions [5]. OME can also be used as fuels in fuel cells $[6,7]$, as solvents for producing hydrogen peroxide [8], and as physical solvents for absorbing $\mathrm{CO}_{2}$ in gas treatment processes $[9,10]$.

OME can be produced in a non-aqueous environment from trioxane and methylal $[4,11,12]$. Trioxane and methylal can both be produced from methanol, with formaldehyde as intermediate $[13,14]$. However, that route involves several elaborate steps. More recent research shows that OME can be produced directly from formaldehyde and methanol without intermediate products [15-20]. As solutions of formaldehyde and methanol usually contain water and stoichiometric amounts of water are formed as a coupled product in the OME synthesis from formaldehyde and methanol [19, 20], a unit for the separation of water is necessary in such a process.

Water has to be separated from mixtures containing the components formaldehyde, water, methanol, methylal, and OME [21, 22]. These mixtures are inherently reactive multicomponent mixtures as formaldehyde reacts with water and methanol to poly(oxymethylene) glycols and poly(oxymethylene) hemiformals without adding a catalyst [23, 24]. Caused by several azeotropes, distillation is not a preferred option for the separation of water from these mixtures [22]. In the scientific literature, also adsorption has been discussed as an option to separate water from these mixtures and results from preliminary experiments are reported showing that this is feasible [22]. The separation of water by a membrane process was suggested [21, 22]. No supporting experimental data were, however, reported so far. This gap is closed in the present work in order to show the feasibility of this separation. 
In a study of a similar chemical system, Carretier et al. [25] investigated a pervaporation process for the separation of water and/or methanol from mixtures of water, methanol, and methylal. Both zeolite and poly(vinyl alcohol) (PVA) membranes were used. Formaldehyde was not present in the studied mixtures, probably because it was quantitatively consumed in the reaction of formaldehyde and methanol to methylal [26].

In the patent literature approaches are described, in which water is separated from formaldehyde-containing mixtures using membrane processes. Chiang et al. [27] suggest various copolymer membranes, which eventually also contain ionic groups, to separate water from mixtures of formaldehyde, water, and methanol by pervaporation. Dams et al. [28] describe a hybrid process, which uses distillation and pervaporation for concentrating an aqueous formaldehyde solution. In the pervaporation unit, a PVA membrane is used to obtain a water-rich permeate and a formaldehyde-rich retentate stream. A PVA membrane was also used by Vandenmersch et al. [29] for the separation of water from mixtures of formaldehyde, water, and methanol by hydrophilic pervaporation. Himeno et al. [30] claim ceramic membranes with 4A-type or T-type zeolites for the separation of water from mixtures of formaldehyde, water, methanol, and carboxylic acid esters, such as methyl propionate. Himeno et al. [30] concurrently mention that their mixtures might additionally contain methylal and OME.

In the present work, a pervaporation process is investigated, in which water is separated from mixtures of formaldehyde, water, methanol, methylal, and $\mathrm{OME}_{2}$. Five commercial membranes were studied: two zeolite membranes (Type NaA and Type T from Mitsui \& Co.) and three PVA-based 
polymer membranes (PERVAP 4100, PERVAP 4101, and PERVAP 4102 from DeltaMem AG). The membrane flux and the composition of the permeate is measured. The zeolite membranes were tested at $343 \mathrm{~K}$ and 7 mbar permeate pressure and the polymer membranes were tested at $353 \mathrm{~K}$ and 2 mbar permeate pressure. The membrane stability against formaldehydecontaining mixtures is investigated by repeat measurements. As criterion, whether a tested membrane is suitable in an OME production process, it has to yield water mass fractions of about $\geq 0.9 \mathrm{~g} / \mathrm{g}$ in the permeate for mass fractions of water between $0.05 \mathrm{~g} / \mathrm{g}$ and $0.01 \mathrm{~g} / \mathrm{g}$ in the feed.

\section{Chemical reactions}

Formaldehyde $\left(\mathrm{FA}, \mathrm{CH}_{2} \mathrm{O}\right)$ reacts with water $\left(\mathrm{H}_{2} \mathrm{O}\right)$ to poly(oxymethylene) glycols $\left(\mathrm{MG}_{n}, \mathrm{HO}-\left(\mathrm{CH}_{2} \mathrm{O}\right)_{n}-\mathrm{H}\right)$ and with methanol $\left(\mathrm{MeOH}, \mathrm{CH}_{3} \mathrm{OH}\right)$ to poly(oxymethylene) hemiformals $\left(\mathrm{HF}_{n}, \mathrm{HO}-\left(\mathrm{CH}_{2} \mathrm{O}\right)_{n}-\mathrm{CH}_{3}\right)$ without adding a catalyst, c.f. reactions (I) to (IV) $[23,24]$.

$$
\begin{aligned}
\mathrm{FA}+\mathrm{H}_{2} \mathrm{O} & \rightleftharpoons \mathrm{MG}_{1} \\
\mathrm{FA}+\mathrm{MG}_{n-1} & \rightleftharpoons \mathrm{MG}_{n} ; n \geq 2 \\
\mathrm{FA}+\mathrm{MeOH} & \rightleftharpoons \mathrm{HF}_{1} \\
\mathrm{FA}+\mathrm{HF}_{n-1} & \rightleftharpoons \mathrm{HF}_{n} ; n \geq 2
\end{aligned}
$$

The chemical equilibrium of reactions (I) and (III) in the liquid phase is far on the side of the products $[23,24]$. When water is separated from these mixtures by pervaporation, the species distribution in chemical equilibrium is changed. As water is removed from the reaction network, formaldehyde previously bound in the poly(oxymethylene) glycols is then increasingly bound in the 
poly(oxymethylene) hemiformals. As long as no strong acids are present, OME and methylal are inert $[19,26]$. This is the case in the pervaporation experiments carried out in the present work.

In mixtures of formaldehyde, water, and methanol, the composition can be described in two different ways. The true concentrations include the poly(oxymethylene) glycols and poly(oxymethylene) hemiformals and can only be determined by methods like NMR spectroscopy. In specifying overall concentrations, the formation of the poly(oxymethylene) glycols and poly(oxymethylene) hemiformals is disregarded, i.e. these compounds are treated as if they were split into formaldehyde, water, and methanol. The overall concentrations can be measured by conventional analysis as described below.

A typical overall composition of the feed stream of the pervaporation experiments is: $0.20 \mathrm{~g} / \mathrm{g}$ formaldehyde, $0.05 \mathrm{~g} / \mathrm{g}$ water, $0.15 \mathrm{~g} / \mathrm{g}$ methanol, $0.40 \mathrm{~g} / \mathrm{g}$ methylal and $0.20 \mathrm{~g} / \mathrm{g} \mathrm{OME}_{2}$. The corresponding true composition in chemical equilibrium at $353 \mathrm{~K}$ is illustrated in Figure 1. It was calculated using the model of the chemical equilibrium of reactions (I) to (IV) of Hahnenstein et al. [23] In the calculations, the chain length of the poly(oxymethylene) glycols and poly(oxymethylene) hemiformals is limited to $n=10$, as higher oligomers are present only in negligible amounts, c.f. Figure 1. The true mass fraction of water is calculated to be $0.042 \mathrm{~g} / \mathrm{g}$. It is thus smaller than the overall mass fraction of water. Figure 1 illustrates that in the pervaporation that is studied in the present work, water is in fact not separated from a five component system, but from a reactive system with about 20 components. 


\section{Experiments}

\subsection{Chemicals}

Methanolic formlaldehyde solutions were prepared by dissolving paraformaldehyde (>0.95 g/g, Carl Roth) in methanol (>0.999 g/g, Sigma Aldrich) at elevated temperatures [19]. Pure water was produced with a Milli-Q water purification system from Merck. The solutions used for the pervaporation experiments were prepared by mixing of methanolic formaldehyde solution, water, methylal (>0.99 g/g, Sigma Aldrich) and $\mathrm{OME}_{2}(>0.98 \mathrm{~g} / \mathrm{g}, \mathrm{OME}$ Technologies).

\subsection{Analysis}

The overall mass fractions of methanol, methylal, and $\mathrm{OME}_{2}$ were analyzed by gas chromatography using 1,4-dioxane as internal standard. A flame ionisation detector was used for the signal detection. More details on the gas chromatographic method are given in previous work [19]. The relative uncertainty for the overall mass fractions is $5 \%$ for methanol and $2 \%$ for methylal and $\mathrm{OME}_{2}$ [19]. The overall mass fraction of formaldehyde was analyzed using the sodium sulfite titration method with hydrochloric acid as titrant. The overall mass fraction of water was analyzed by Karl Fischer titration. The relative uncertainty is $2 \%$ for the overall mass fraction of formaldehyde and water [19].

For the first feed sample (start of the pervaporation) and the last feed sample (end of the pervaporation), the overall mass fractions of all components were analyzed and normalized to a sum of $1 \mathrm{~g} / \mathrm{g}$ by proportional weighting. The sum of the non-normalized overall mass fractions was be- 
tween $0.97 \mathrm{~g} / \mathrm{g}$ and $1.02 \mathrm{~g} / \mathrm{g}$ in all cases. For all other feed samples, only the overall mass fraction of water was analyzed. The water-rich permeate samples were analyzed for the overall mass fraction of formaldehyde, methanol, methylal, and $\mathrm{OME}_{2}$. The overall mass fraction of water was calculated as complement to $1 \mathrm{~g} / \mathrm{g}$.

\subsection{Experimental set-up and procedure}

The pervaporation experiments were carried out in a pervaporation unit from DeltaMem AG, Switzerland. A flowsheet is shown in Figure 2. The double-jacketed feed tank is thermostated. From the feed tank, the mixture can either be pumped over a flat module containing a polymer membrane or a tubular module containing a ceramic membrane. The retentate is circulated back to the feed tank. For the start up of the unit, the feed mixture is heated such that the temperature in the tank is about $10 \mathrm{~K}$ higher than the desired operating temperature of the pervaporation. During the start-up, the mixture is circulated in a loop and thus not brought into contact with a membrane module. Then, the valves are switched such that the mixture is pumped through the desired membrane module. The flowrate on the feed side is adjusted by bypass and throttle control of the pump to about $80 \mathrm{l} / \mathrm{h}$. On the permeate side, vacuum is applied using a vacuum pump. The pressure on the permeate side is measured (vacuubrand DVR 2, \pm 1 mbar). The permeate is frozen out in a round bottom flask that is immersed in a dewar filled with liquid nitrogen.

After the temperatures measured at the inlet and outlet of the the membrane module had reached the desired operating temperature, the permeate collection was started. The deviation of both temperatures was always below 
1.5 K. This is considered to be the uncertainty of the temperatures of the pervaporation experiments. The overall membrane fluxes of water $\tilde{J}_{\mathrm{H}_{2} \mathrm{O}}$ are determined by weighing of the mass of permeate $m_{\text {Perm }}$ collected over a sampling period $\Delta t$ and the result of the analysis of the permeate, c.f. Eq. (1),

$$
\tilde{J}_{\mathrm{H}_{2} \mathrm{O}}=\tilde{x}_{\mathrm{H}_{2} \mathrm{O}, \text { Perm }}^{(m)} \cdot \frac{m_{\text {Perm }}}{A_{\text {Membrane }} \cdot \Delta t}
$$

where $\tilde{x}_{\mathrm{H}_{2} \mathrm{O} \text {,Perm }}^{(m)}$ is the overall mass fraction of water in the permeate, and $A_{\text {Membrane }}$ is the membrane area. At the beginning and at the end of a sampling period $\Delta t$, a sample from the feed mixture is taken through the feed sampling valve. Starting from mixtures with an overall mass fraction of water of about 0.15 to $0.25 \mathrm{~g} / \mathrm{g}$ (first sample), the mixtures were depleted of water to reach an overall mass fraction of about $0.01 \mathrm{~g} / \mathrm{g}$ (last sample). The overall concentrations of the further components formaldehyde, methanol, methylal, and $\mathrm{OME}_{2}$ were motivated by the typical process composition of the feed stream for the OME production process as discussed above. Exact values are reported below. For one sampling period $\Delta t$, the overall mass fraction of water in the feed is calculated as the geometric mean of the overall mass fractions of water determined at the beginning and at the end of the sampling period. Sampling periods were between 20 and 185 minutes depending on the overall mass fraction of water in the feed. The total experimental operation for one dehydration was about one day. In some cases, dehydration was continued on the next day. Exact values are given in the Supplementary Information. A repeat measurement was carried out 2 - 3 days after testing the new membrane. The membrane sample remained in the pervaporation unit at room temperature between the test of the new membrane and the 
repeat measurement. In case of the polymer membranes, the vacuum pump was kept running to prevent damage of the membrane.

\subsection{Membranes}

\subsubsection{Ceramic membranes}

The investigated ceramic membranes are commercial zeolite membranes, Type NaA and Type T from Mitsui \& Co. The tubular membranes consist of a zeolite separation layer and a ceramic support. According to the manufacturer information, Type NaA zeolites are more hydrophilic. Type T zeolites are, however, expected to be more stable against acids [31]. The membrane area of the module that was used in the present study was $56.5 \mathrm{~cm}^{2}$.

\subsubsection{Polymer membranes}

The investigated polymer membranes are commercial PVA membranes, PERVAP 4100, PERVAP 4101, and PERVAP 4102 from DeltaMem AG. The PVA separation layer is cross-linked in different ways in the series 410X. For all three types, the separation layer is placed on a porous poly(acrylonitrile) support layer and a polyester fleece. According to the manufacturer information, PERVAP 4100 is a moderately cross-linked standard membrane, whereas PERVAP 4101 and PERVAP 4102 are highly cross-linked membranes. DeltaMem provides guidance of these membranes for aldehyde concentrations $<30 \mathrm{ppm}$. Despite this, the membranes were tested in the present work. The membrane area of the module that was used in the present study was $160 \mathrm{~cm}^{2}$. 


\subsection{Experimental program}

In the present work, the overall membrane fluxes and the overall composition of the permeate were measured for all 5 membranes employing both a new membrane as well as a membrane that had been used previously. By employing a used membrane in the repeat measurement, preliminary information on the membrane stability is gained. The investigated temperatures were $343 \mathrm{~K}$ for the ceramic membranes Type NaA and Type $\mathrm{T}$ and $353 \mathrm{~K}$ for the polymer membranes of the series 410X. The temperatures are well below the recommended maximum long term operating temperatures. The permeate pressure was 7 mbar for the ceramic membranes Type NaA and Type $\mathrm{T}$ and 2 mbar for the polymer membranes of the series $410 \mathrm{X}$. The slight difference is caused by different air leakage rates of the two modules (either ceramic or polymer). The volumetric flowrate was set to $80 \mathrm{l} / \mathrm{h}$ for all experiments. This value is recommended by DeltaMem for ethanol dehydration and was adopted here. This flowrate paired with rather low viscosities of the studied mixtures makes concentration polarization unlikely.

\subsection{Experimental results}

Numerical results for the overall membrane flux of water and the overall composition of the permeate obtained in the experiments with the different membranes are reported in the Supplementary Information, both for the experiments with the new membranes, as well as for the repeat experiments with used membranes. Graphical representations are given below. The numerical values of the overall composition of all components for the first and the last feed sample of each experiment are reported in Table 1. The experimental results are discussed below. 


\section{Discussion of experimental results}

\subsection{Ceramic membrane Type NaA}

The experimental overall water fluxes and the overall mass fractions of water in the permeate obtained in the experiment with the ceramic membrane Type NaA are shown in Figure 3. For the new membrane, the overall mass fraction of water in the permeate is $\geq 0.9886 \mathrm{~g} / \mathrm{g}$. The main impurity in the permeate is formaldehyde, for which the overall mass fraction in the permeate is between $0.0017 \mathrm{~g} / \mathrm{g}$ and $0.0028 \mathrm{~g} / \mathrm{g}$. The membrane does, however, not perform well in the repeat measurement. Both, the overall water flux and the overall mass fractions of water are significantly reduced compared to the experiment with the new membrane. However, water is still enriched in the permeate. This was also observed for a second membrane of Type NaA. Cleaning of the membrane with water was not successful. Following this, rather a structural damage of the zeolite framework is assumed. In future work, gas permeation test could be carried out to confirm this. In formaldehyde-containing solutions usually small amounts of formic acid are present [32]. Acids may lead to dissolution of the zeolite framework and a loss of membrane performance is observed [31]. Thus, the tested membrane of Type NaA is not suitable for the present separation task.

\subsection{Ceramic membrane Type T}

The experimental results for the ceramic membrane of Type $\mathrm{T}$ are shown in Figure 4. It can be seen that the overall water fluxes and the overall mass fractions of water are lower than for the membrane of Type NaA, when a new membrane is used. The overall mass fraction of water in the permeate 
is $\leq 0.8927 \mathrm{~g} / \mathrm{g}$. The main impurity in the permeate is methylal, for which the overall mass fraction is between $0.0382 \mathrm{~g} / \mathrm{g}$ and $0.0487 \mathrm{~g} / \mathrm{g}$. The overall mass fractions of formaldehyde, methanol, and $\mathrm{OME}_{2}$ in the permeate are each $\geq 0.02 \mathrm{~g} / \mathrm{g}$, and thus also comparably high. Caused by these unfavorable results, no repeat measurement was carried out for the membrane of Type $\mathrm{T}$, which is not suited for the present separation task.

\subsection{Polymer membrane PERVAP 4100}

Figure 5 shows the experimental results for the membrane PERVAP 4100. In the experiments with the new membrane as well as in the repeat experiment, the overall mass fraction of water in the permeate is $\geq 0.9537 \mathrm{~g} / \mathrm{g}$. The results from the repeat measurement show slightly higher overall water fluxes and lower overall mass fractions of water in the permeate than those from the experiments with the new membrane. The main impurities in the permeate are formaldehyde and methanol, for which the overall mass fraction in the permeate are between $0.0042 \mathrm{~g} / \mathrm{g}$ and $0.0142 \mathrm{~g} / \mathrm{g}$ (formaldehyde) and $0.0078 \mathrm{~g} / \mathrm{g}$ and $0.0222 \mathrm{~g} / \mathrm{g}$ (methanol). Thus, the membrane PERVAP 4100 is in principle suitable for the separation of water from the investigated system. However, studies of the long-term stability would be necessary to confirm this. Formaldehyde is likely to react with the hydroxyl groups of PVA in a similar manner as it reacts with methanol, c.f. reactions (III) and (IV). These reactions are, however, reversible. Thus, formaldehyde eventu-

ally linked chemically to the hydroxyl group of PVA could be removed by washing with water or methanol. 


\subsection{Polymer membrane PERVAP 4101}

Figure 6 shows the experimental results for the membrane PERVAP 4101. The experiment with a new membrane and the repeat measurement show overall mass fractions of water in the permeate $\geq 0.9793 \mathrm{~g} / \mathrm{g}$. The overall water fluxes and overall mass fractions of water in the permeate are almost identical for both experiments. Compared to the membrane PERVAP 4100, the overall water fluxes are lower, whereas the overall mass fractions of water in the permeate are higher. This can be explained by the higher degree of cross-linking of PERVAP 4101 compared to PERVAP 4100. Again, the main impurities in the permeate are formaldehyde and methanol, for which the overall mass fractions are between $0.0012 \mathrm{~g} / \mathrm{g}$ and $0.0053 \mathrm{~g} / \mathrm{g}$ (formaldehyde) and $0.0064 \mathrm{~g} / \mathrm{g}$ and $0.0126 \mathrm{~g} / \mathrm{g}$ (methanol). Thus, the membrane PERVAP 4101 is also suitable for the separation of water from the investigated system. Again, research on the long-term stability would be necessary to confirm this.

\subsection{Polymer membrane PERVAP 4102}

Figure 7 shows the experimental results for the membrane PERVAP 4102. Compared to the membranes PERVAP 4100 and PERVAP 4101, this membrane shows a distinct decrease of the overall mass fractions of water in the permeate at low overall mass fractions of water in the feed $(\leq 0.05 \mathrm{~g} / \mathrm{g})$. The lowest overall mass fraction of water in the permeate is only $0.5203 \mathrm{~g} / \mathrm{g}$ and was observed in the repeat measurement. The overall water fluxes in the repeat measurement are slightly lower than those in the experiments with the new membrane. The overall water fluxes of the membranes PERVAP 4102 and PERVAP 4101 are similar. For overall mass fractions of water in the 
feed above $0.05 \mathrm{~g} / \mathrm{g}$, the main impurities in the permeate are again formaldehyde and methanol, for which the overall mass fraction in the permeate are between $0.0066 \mathrm{~g} / \mathrm{g}$ and $0.0108 \mathrm{~g} / \mathrm{g}$ (formaldehyde) and $0.0088 \mathrm{~g} / \mathrm{g}$ and $0.0173 \mathrm{~g} / \mathrm{g}$ (methanol). For overall mass fractions of water in the feed below $0.05 \mathrm{~g} / \mathrm{g}$, however, larger amounts of impurities are found in the permeate. The main impurity is methylal, for which the maximal overall mass fraction is $0.1709 \mathrm{~g} / \mathrm{g}$, which is observed in the repeat measurement. For the OME production process, overall mass fractions of water in the feed $\leq 0.05 \mathrm{~g} / \mathrm{g}$ are expected, see above. Thus the membrane PERVAP 4102 is not well suited for the present separation task.

\section{Integrating pervaporation into the OME production process}

\subsection{Flowsheet}

An OME production process, which produces OME from formaldehyde and methanol has been described in detail by Schmitz et al. [22] It is briefly discussed here to point out the relevance of the pervaporation unit as part of the OME production. A flowsheet of the process is shown in Figure 8. The feed stream 1 of the process contains formaldehyde and methanol and usually also water. It is mixed with two recycle streams 7 and 9 to obtain stream 2, which is fed into the reactor that contains a heterogeneous acidic catalyst. The reactor outlet stream contains the components formaldehyde, water, methanol, methylal, and OME of various chain lengths. The OME of chain lengths $n=3-5$ (stream 6 ) are separated from the reactor outlet in two distillation columns $\mathrm{C} 1$ and $\mathrm{C} 2$. The overhead product from the first column, stream 4, contains mainly the components formaldehyde, water, 
methanol, methylal and $\mathrm{OME}_{2}$. It might also contain smaller amounts of OME with $n \geq 3$. The overall mass fraction of water in stream 4 is between $0.04 \mathrm{~g} / \mathrm{g}$ and $0.06 \mathrm{~g} / \mathrm{g}$ [22]. Stream 4 is the feed stream for the pervaporation unit. It separates stream 4 into a permeate stream 8, which is almost pure water, and a water-depleted retentate stream 9 . The overall mass fraction of water in the retenate stream 9 should be about $0.01 \mathrm{~g} / \mathrm{g}$ [22]. When a partial condenser is used at the top of distillation column $\mathrm{C} 1$, the membrane process could in principle also be operated in vapor permeation mode. It should be investigated in future work how stream 8 is further processed. It could be used for quenching the reactor outlet in the formaldehyde production process or alternatively, it could be treated in as waste water. State-of-the-art waste water processes should be treated as sufficient.

\subsection{Estimation of membrane area}

The experimental overall water fluxes $\tilde{J}_{\mathrm{H}_{2} \mathrm{O}}$ were correlated for all membranes as function of the overall mass fraction of water $\tilde{x}_{\mathrm{H}_{2} \mathrm{O}}^{(m)}$ by Eq. (2).

$$
\tilde{J}_{\mathrm{H}_{2} \mathrm{O}}=a \cdot\left(1-e^{-b \cdot \tilde{x}_{\mathrm{H}_{2} \mathrm{O}}^{(m)}}\right)
$$

The parameters $a$ and $b$ were fitted to the experimental fluxes. The correlations are indicated as solid lines in Figures 3 to 7 . The parameters $a$ and $b$ are given in Table 2 for the two promising membranes PERVAP 4100 and PERVAP 4101. The correlation for $\tilde{J}_{\mathrm{H}_{2} \mathrm{O}}$ is used to calculate the necessary membrane area by Eq. (3), which can be derived from a differential mass balance of water along the membrane. The derivation is given in the 
Supplementary Information.

$$
A_{\text {Membrane }}=\frac{\dot{m}_{\mathrm{Feed}}}{a \cdot b} \cdot \ln \left(\frac{e^{b \cdot \tilde{x}_{\mathrm{H}_{2} \mathrm{O}, \mathrm{Feed}}^{(m)}}-1}{e^{b \cdot \tilde{x}_{\mathrm{H}_{2} \mathrm{O}, \mathrm{Ret}}^{(m)}}-1}\right)
$$

In Eq. (3), $\dot{m}_{\text {Feed }}$ is the mass flow of the pervaporation feed stream 4, and $\tilde{x}_{\mathrm{H}_{2} \mathrm{O} \text {,Feed }}^{(m)}$ and $\tilde{x}_{\mathrm{H}_{2} \mathrm{O} \text {,Ret }}^{(m)}$ are the overall mass fractions of the pervaporation feed stream 4 and the retentate stream 9, respectively. In previous work on the OME production process [22], we have published stream tables of two operating points of the OME process that were calculated using a simplified process model. The data were used here to estimate the necessary membrane area based on Eq. (3). For the membrane PERVAP 4101, the estimated membrane area is between $0.24 \mathrm{~m}^{2}$ (operating point 1 of [22]) and $0.39 \mathrm{~m}^{2}$ (operating point 2 of [22]) for producing $1 \mathrm{~kg} / \mathrm{h}$ product. The difference between the two operating points is that in operating point 2, a larger amount of water is fed to the process through stream 1 [22], leading to a larger membrane area that is necessary for the separation. This calculation requires that the pervaporation would be operated at a temperature of $353 \mathrm{~K}$ and a permeate pressure of 2 mbar, which might, however, not be a desirable operating point of an industrial pervaporation process, e.g. the temperature could be increased to reduce the necessary membrane area. The corresponding numbers for the membrane PERVAP 4100 are $0.18 \mathrm{~m}^{2}$ (operating point 1 of [22]) and $0.29 \mathrm{~m}^{2}$ for producing $1 \mathrm{~kg} / \mathrm{h}$ product (operating point 2 of [22]).

\section{Conclusions}

In the present work the separation of water from mixtures containing formaldehyde, water, methanol, methylal, and poly(oxymethylene) dimethyl 
ethers (OME) by pervaporation was investigated experimentally. This separation is important for a new production process for OME. The investigated mixtures are inherently reactive mixtures as formaldehyde reacts both with water and methanol to poly(oxymethylene) glycols and poly(oxymethylene) hemiformals. Despite the complexity of these mixtures, the pervaporation was found to be feasible. The ceramic membrane Type NaA performs well when a new membrane is used. It is, however, not stable. The ceramic membrane Type $\mathrm{T}$ shows low overall water fluxes and low overall mass fractions of water in the permeate. Experiments with the polymeric membranes, PERVAP 4100, PERVAP 4101, and PERVAP 4102 yielded favorable results and the membranes were found to remain stable in a repeat measurement. Further research on the long-term stability of the membranes against the present system is needed. 


\section{Nomenclature}

Abbreviations

FA Formaldehyde

HF Poly(oxymethylene) hemiformal

$\mathrm{MeOH} \quad$ Methanol

MG Poly(oxymethylene) glycol

OME Poly(oxymethylene) dimethyl ether

Perm Permeate

PVA Poly(vinyl alcohol)

Ret Retentae

Symbols and indices

$a, b \quad$ Correlation parameters defined by Eq. (2)

$A_{\text {Membrane }}$ Membrane area

$\tilde{J}_{\mathrm{H}_{2} \mathrm{O}} \quad$ Overall flux of water

$\dot{m} \quad$ Mass flow

$m_{\text {Perm }} \quad$ Mass of permeate

n Oligomer chain length

$\Delta t \quad$ Permeate sampling period

$\tilde{x}_{\mathrm{H}_{2} \mathrm{O}}^{(m)} \quad$ Overall mass fraction of water 


\section{Acknowledgement}

This work was funded by the German Federal Ministry of Food and Agriculture (BMEL) through grant 22403914. 


\section{References}

[1] B. Lumpp, D. Rothe, C. Pastötter, R. Lämmermann, E. Jacob, Oxymethylene ethers as diesel fuel additives of the future, MTZ 72 (3) (2011) 34-38.

[2] M. Härtl, P. Seidenspinner, E. Jacob, G. Wachtmeister, Oxygenate screening on a heavy-duty diesel engine and emission characteristics of highly oxygenated oxymethylene ether fuel OME1, Fuel 153 (2015) 328335.

[3] J. Burger, M. Siegert, E. Ströfer, H. Hasse, Poly(oxymethylene) dimethyl ethers as components of tailored diesel fuel: Properties, synthesis and purification concepts, Fuel 89 (11) (2010) 3315-3319.

[4] J. Burger, A novel process for the production of diesel fuel additives by hierarchical design, Ph.D. thesis, TU Kaiserslautern, Kaiserslautern (2012).

[5] M. Härtl, K. Gaukel, D. Pélerin, G. Wachtmeister, Oxymethylenether als potenziell $\mathrm{CO}_{2}$-neutraler Kraftstoff für saubere Dieselmotoren Teil 1: Motorenuntersuchungen, MTZ 78 (2) (2017) 52-59.

[6] S. Baranton, H. Uchida, D. A. Tryk, J. L. Dubois, M. Watanabe, Hydrolyzed polyoxymethylenedimethylethers as liquid fuels for direct oxidation fuel cells, Electrochim. Acta 108 (2013) 350-355.

[7] D. Devaux, H. Yano, H. Uchida, J.-L. Dubois, M. Watanabe, Electrooxidation of hydrolysed poly-oxymethylene-dimethylether on PtRu supported catalysts, Electrochim. Acta 56 (3) (2011) 1460-1465. 
[8] Q. Liu, X. Zhang, B. Ma, Solubility of 2-ethylanthraquinone in binary mixtures of oligooxymethylene dimethyl ethers with different number of $\mathrm{CH}_{2} \mathrm{O}$ groups of $n=2,3$, and 4 from 293.15 to $343.15 \mathrm{~K}$, J. Chem. Eng. Data 61 (9) (2016) 3254-3265.

[9] J. Burger, V. Papaioannou, S. Gopinath, G. Jackson, A. Galindo, C. S. Adjiman, A hierarchical method to integrated solvent and process design of physical $\mathrm{CO}_{2}$ absorption using the SAFT- $\gamma$ mie approach, AIChE J. 61 (10) (2015) 3249-3269.

[10] M. Schappals, T. Breug-Nissen, K. Langenbach, J. Burger, H. Hasse, Solubility of carbon dioxide in poly(oxymethylene) dimethyl ethers, J. Chem. Eng. Data 62 (11) (2017) 4027-4031.

[11] J. Burger, H. Hasse, Multi-objective optimization using reduced models in conceptual design of a fuel additive production process, Chem. Eng. Sci. 99 (2013) 118-126.

[12] J. Burger, E. Ströfer, H. Hasse, Chemical equilibrium and reaction kinetics of the heterogeneously catalyzed formation of poly(oxymethylene) dimethyl ethers from methylal and trioxane, Ind. Eng. Chem. Res. 51 (39) (2012) 12751-12761.

[13] T. Grützner, H. Hasse, N. Lang, M. Siegert, E. Ströfer, Development of a new industrial process for trioxane production, Chem. Eng. Sci. $62(18-20)(2007)$ 5613-5620.

[14] J.-O. Weidert, J. Burger, M. Renner, S. Blagov, H. Hasse, Develop- 
ment of an integrated reaction-distillation process for the production of methylal, Ind. Eng. Chem. Res. 56 (2) (2017) 575-582.

[15] J. Zhang, D. Fang, D. Liu, Evaluation of Zr-alumina in production of polyoxymethylene dimethyl ethers from methanol and formaldehyde: Performance tests and kinetic investigations, Ind. Eng. Chem. Res. 53 (35) (2014) 13589-13597.

[16] J. Zhang, M. Shi, D. Fang, D. Liu, Reaction kinetics of the production of polyoxymethylene dimethyl ethers from methanol and formaldehyde with acid cation exchange resin catalyst, React. Kinet. Mech. Cat. 11 (2) (2014) 459-470.

[17] D. Oestreich, L. Lautenschütz, U. Arnold, J. Sauer, Reaction kinetics and equilibrium parameters for the production of oxymethylene dimethyl ethers (ome) from methanol and formaldehyde, Chem. Eng. Sci. 163 (2017) 92-104.

[18] D. Oestreich, L. Lautenschütz, U. Arnold, J. Sauer, Production of oxymethylene dimethyl ether (OME)-hydrocarbon fuel blends in a onestep synthesis/extraction procedure, Fuel 214 (2018) 39-44.

[19] N. Schmitz, F. Homberg, J. Berje, J. Burger, H. Hasse, Chemical equilibrium of the synthesis of poly(oxymethylene) dimethyl ethers from formaldehyde and methanol in aqueous solutions, Ind. Eng. Chem. Res. 54 (25) (2015) 6409-6417.

[20] N. Schmitz, J. Burger, H. Hasse, Reaction kinetics of the formation of 
poly(oxymethylene) dimethyl ethers from formaldehyde and methanol in aqueous solutions, Ind. Eng. Chem. Res. 54 (50) (2015) 12553-12560.

[21] U. Arnold, L. Lautenschütz, D. Oestreich, J. Sauer, Verfahren zur Herstellung von Oxymethylenethern und deren Verwendung (EP 2987781), 2016.

[22] N. Schmitz, E. Ströfer, J. Burger, H. Hasse, Conceptual design of a novel process for the production of poly(oxymethylene) dimethyl ethers from formaldehyde and methanol, Ind. Eng. Chem. Res. 56 (40) (2017) 11519-11530.

[23] I. Hahnenstein, M. Albert, H. Hasse, C. G. Kreiter, G. Maurer, NMR spectroscopic and densimetric study of reaction kinetics of formaldehyde polymer formation in water, deuterium oxide, and methanol, Ind. Eng. Chem. Res. 34 (2) (1995) 440-450.

[24] I. Hahnenstein, H. Hasse, C. G. Kreiter, G. Maurer, 1H- and 13C-NMRspectroscopic study of chemical equilibria in solutions of formaldehyde in water, deuterium oxide, and methanol, Ind. Eng. Chem. Res. 33 (4) (1994) 1022-1029.

[25] E. Carretier, P. Moulin, M. Beaujean, F. Charbit, Purification and dehydration of methylal by pervaporation, J. Membr. Sci. 217 (1-2) (2003) 159-171.

[26] J.-O. Drunsel, M. Renner, H. Hasse, Experimental study and model of reaction kinetics of heterogeneously catalyzed methylal synthesis, Chem. Eng. Res. Des. 90 (5) (2012) 696-703. 
[27] R. Chiang, E. Perry, Process for separating aqueous formaldehyde mixtures (US 4035291), 1977.

[28] A. Dams, A. Fried, F. Hammann, Process for the production of concentrated aqueous formaldehyde solutions by pervaporation (EP 0652201), 1995.

[29] H. Vandenmersch, T. Sirch, C. Hittinger, E. Danz, Preparation of alcohol formaldehyde solution, using a membrane selective process with water removal, and suitable for preparing ether type aminoplast resins (DE 10004562), 2001.

[30] Y. Himeno, K. Ooyachi, M. Kondo, Dehydration of water containing source of formaldehyde, and a method for producing an ethylenically unsaturated carboxylic ester (WO 2013121594), 2013.

[31] Y. Cui, H. Kita, K.-I. Okamoto, Zeolite T membrane: Preparation, characterization, pervaporation of water/organic liquid mixtures and acid stability, J. Membr. Sci. 236 (1-2) (2004) 17-27.

[32] H. Hasse, Dampf-Flüssigkeits-Gleichgewichte, Enthalpien und Reaktionskinetik in formaldehydhaltigen Mischungen, Ph.D. thesis, TU Kaiserslautern, Kaiserslautern (1990). 
Table 1: Overall composition of the mixtures in the pervaporation experiments. (N: $\triangleright)$ Start of an experiment with a new membrane. (N: $\square$ ) End of an experiment with a new membrane. (R: $\triangleright$ ) Start of a repeat experiment with a used membrane. (R: $\square$ ) End of a repeat experiment with a used membrane.

\begin{tabular}{|c|c|c|c|c|c|c|}
\hline & & \multicolumn{5}{|c|}{ Overall mass fraction / (g/g) } \\
\hline & & Formaldehyde & Water & Methanol & Methylal & $\mathrm{OME}_{2}$ \\
\hline & $\mathrm{N}: \triangleright$ & 0.1490 & 0.2120 & 0.1182 & 0.3433 & 0.1775 \\
\hline Type & $\mathrm{N}: \square$ & 0.1889 & 0.0086 & 0.1511 & 0.4291 & 0.2223 \\
\hline \multirow[t]{2}{*}{$\mathrm{NaA}$} & $\mathrm{R}: \triangleright$ & 0.1665 & 0.1371 & 0.1321 & 0.3732 & 0.1911 \\
\hline & $\mathrm{R}: \square$ & 0.1716 & 0.1229 & 0.1353 & 0.3750 & 0.1951 \\
\hline \multirow{2}{*}{ Type T } & $\mathrm{N}: \triangleright$ & 0.1641 & 0.1587 & 0.1297 & 0.3619 & 0.1856 \\
\hline & $\mathrm{N}: \square$ & 0.1668 & 0.1349 & 0.1342 & 0.3720 & 0.1921 \\
\hline & $N: \triangleright$ & 0.1748 & 0.1406 & 0.1367 & 0.3466 & 0.2014 \\
\hline PERVAP & $\mathrm{N}: \square$ & 0.2026 & 0.0062 & 0.1551 & 0.4018 & 0.2344 \\
\hline \multirow[t]{3}{*}{4100} & $\mathrm{R}: \triangleright$ & 0.1641 & 0.1761 & 0.1328 & 0.3417 & 0.1853 \\
\hline & $\mathrm{R}: \square$ & 0.2024 & 0.0067 & 0.1772 & 0.3868 & 0.2269 \\
\hline & $\mathrm{N}: \triangleright$ & 0.1298 & 0.2578 & 0.1050 & 0.3297 & 0.1776 \\
\hline PERVAP & $\mathrm{N}: \square$ & 0.1750 & 0.0064 & 0.1410 & 0.4324 & 0.2452 \\
\hline \multirow[t]{3}{*}{4101} & $\mathrm{R}: \triangleright$ & 0.1695 & 0.1551 & 0.1361 & 0.3421 & 0.1972 \\
\hline & $\mathrm{R}: \square$ & 0.1994 & 0.0139 & 0.1569 & 0.3973 & 0.2324 \\
\hline & $N: \triangleright$ & 0.1728 & 0.1794 & 0.1337 & 0.3183 & 0.1958 \\
\hline PERVAP & $\mathrm{N}: \square$ & 0.2107 & 0.0071 & 0.1598 & 0.3802 & 0.2422 \\
\hline \multirow[t]{2}{*}{4102} & $\mathrm{R}: \triangleright$ & 0.1573 & 0.1822 & 0.1449 & 0.3283 & 0.1873 \\
\hline & $\mathrm{R}: \square$ & 0.1936 & 0.0060 & 0.1720 & 0.3948 & 0.2335 \\
\hline
\end{tabular}


Table 2: Parameters $a$ and $b$ for the calculation of the overall water fluxes according to Eq. (2). The parameters are valid for a temperature of $353 \mathrm{~K}$, a permeate pressure of 2 mbar and a volumetric feed flow rate of $80 \mathrm{l} / \mathrm{h}$.

\begin{tabular}{ccc}
\hline Membrane & $a /\left(\mathrm{kg} \cdot \mathrm{m}^{-2} \cdot \mathrm{h}^{-1}\right)$ & $b$ \\
\hline PERVAP 4100 & 11.642 & 2.600 \\
PERVAP 4101 & 4.988 & 4.718 \\
\hline
\end{tabular}




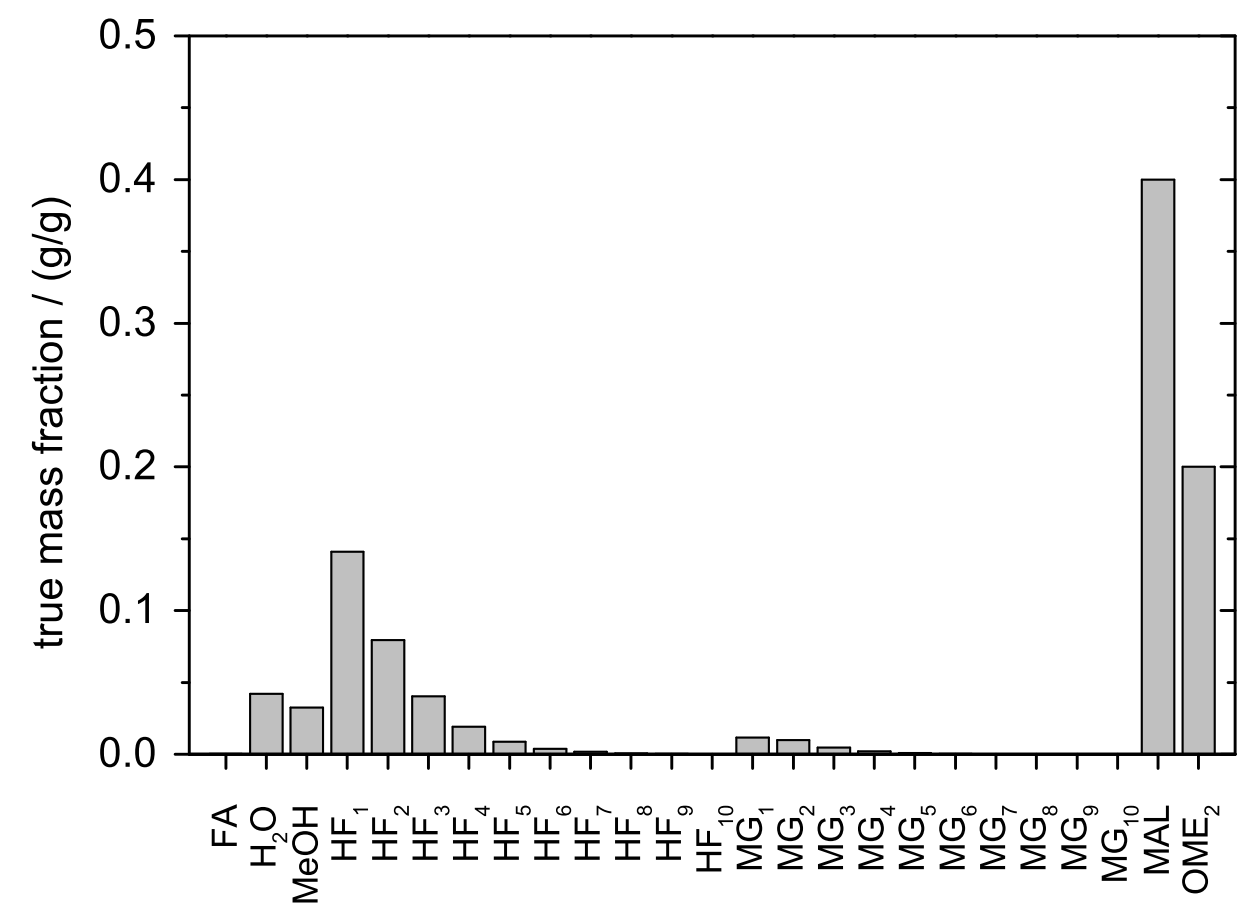

Figure 1: True mass fractions in chemical equilibrium at $353 \mathrm{~K}$ in a mixture with the following overall mass fractions: $0.20 \mathrm{~g} / \mathrm{g}$ formaldehyde, $0.05 \mathrm{~g} / \mathrm{g}$ water, $0.15 \mathrm{~g} / \mathrm{g}$ methanol, $0.40 \mathrm{~g} / \mathrm{g}$ methylal and $0.20 \mathrm{~g} / \mathrm{g} \mathrm{OME}_{2}$. The conditions correspond to a typical feed stream used in the pervaporation experiments. 


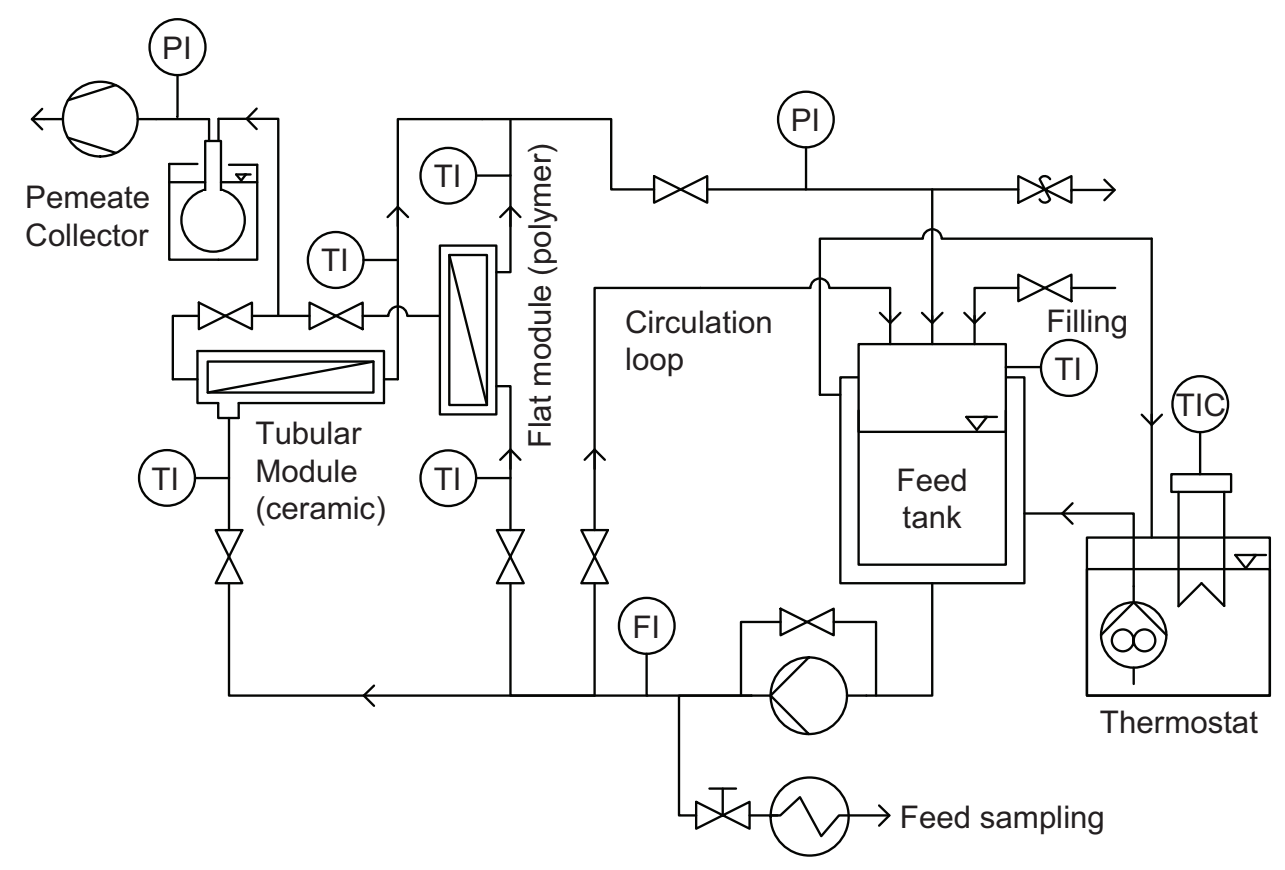

Figure 2: Flowsheet of the pervaporation unit. FI: flow indication: PI: pressure indication: TI: temperature indication. TIC: temperature indication and control. 


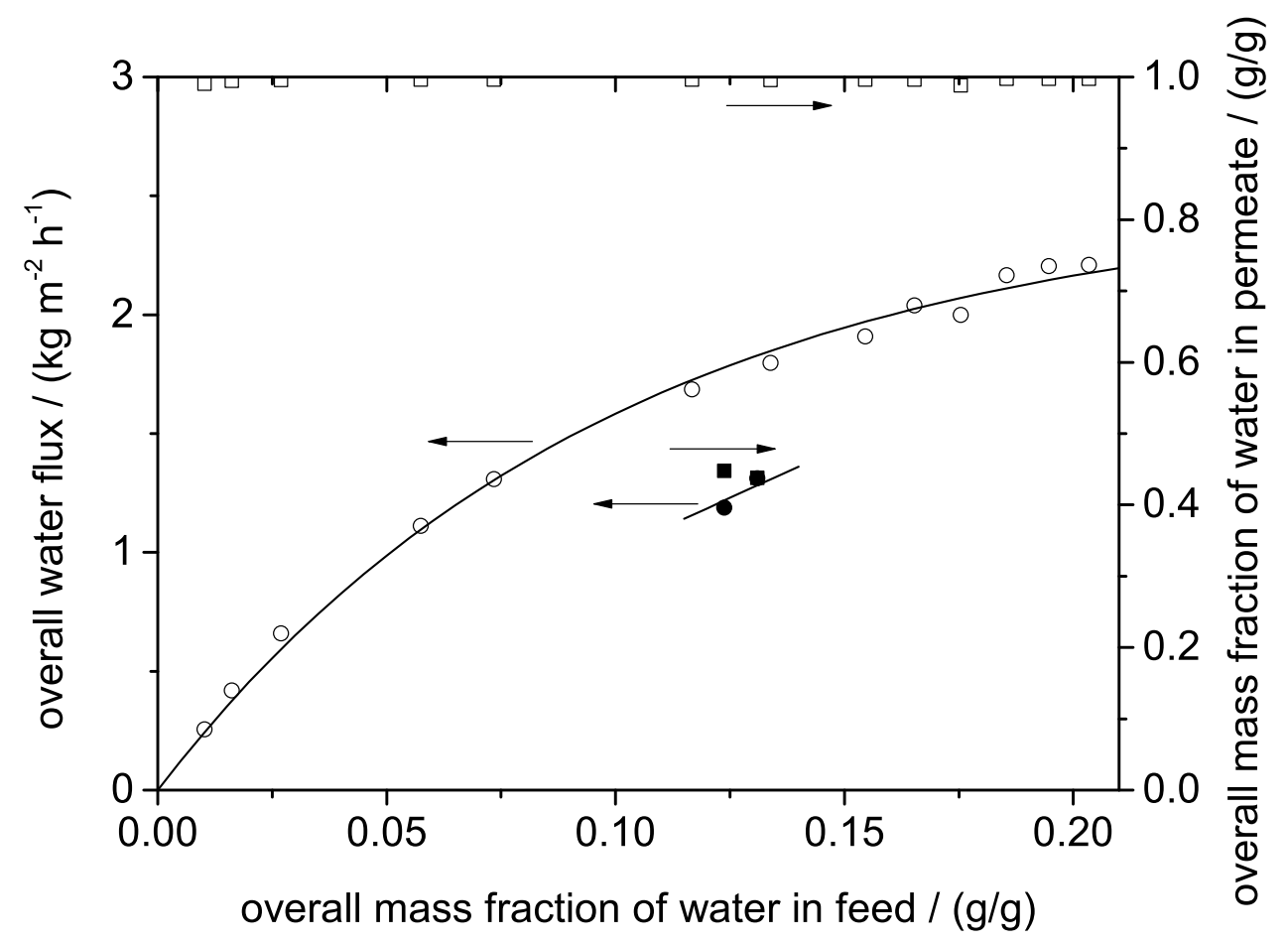

Figure 3: Experimental overall water fluxes $(\circ, \bullet)$ and overall mass fraction of water in the permeate $(\square, \boldsymbol{\square})$ using the ceramic membrane Type NaA for the pervaporation. Open symbols: New membrane. Filled symbols: repeat experiment with used membrane. The temperature is $343 \mathrm{~K}$, the permeate pressure is $7 \mathrm{mbar}$, and the volumetric feed flow rate is $80 \mathrm{l} / \mathrm{h}$. Solid lines: Correlation of the overall water flux using Eq. (2). The overall composition at the start and at the end of the pervaporation experiment is given in Table 1. 


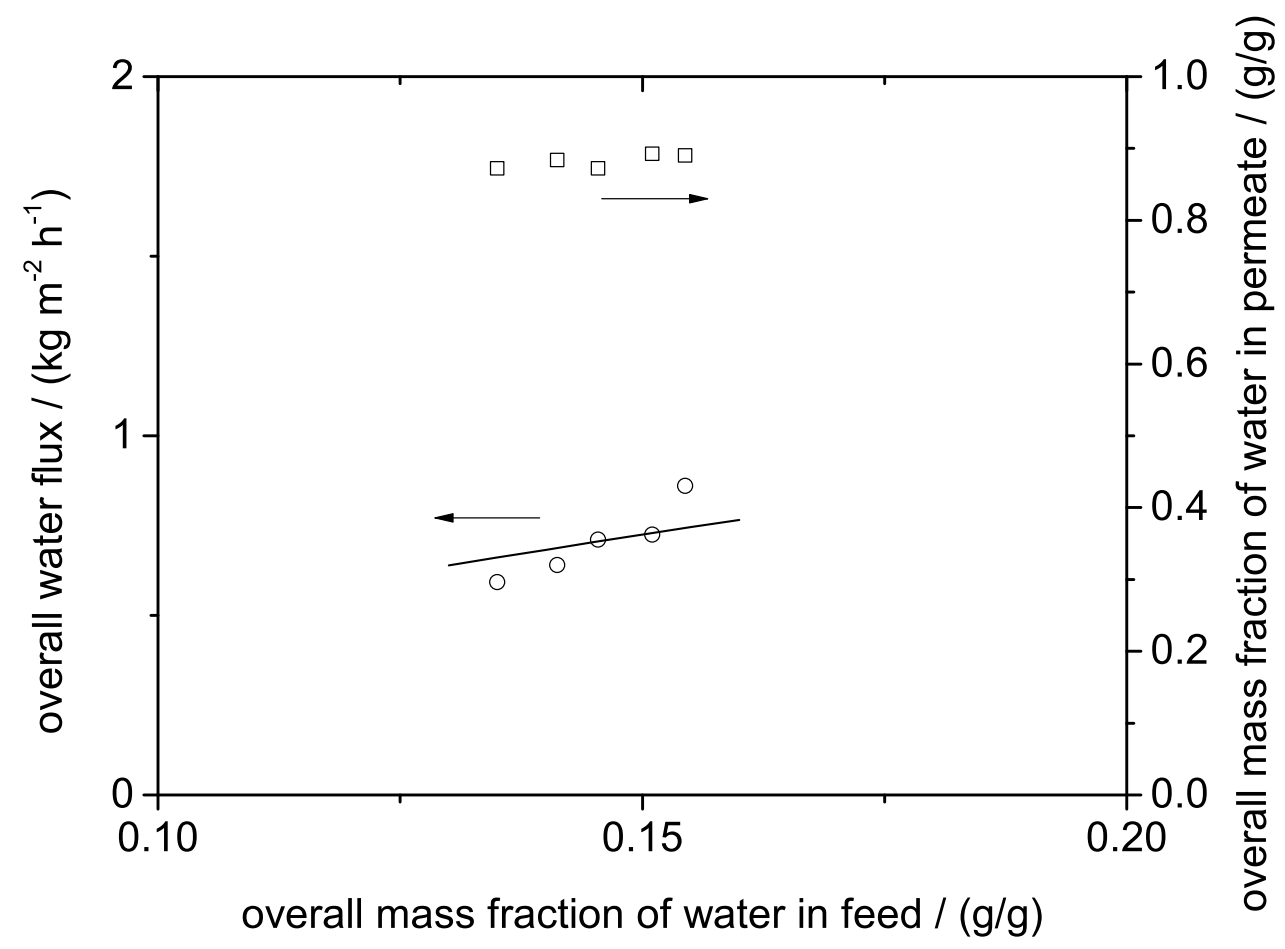

Figure 4: Experimental overall water fluxes (o) and overall mass fraction of water in the permeate $(\square)$ using the ceramic membrane Type $T$ for the pervaporation. A new membrane was used. The temperature is $343 \mathrm{~K}$, the permeate pressure is $7 \mathrm{mbar}$, and the volumetric feed flow rate is $80 \mathrm{l} / \mathrm{h}$. Solid line: Correlation of the overall water flux using Eq. (2). The overall composition at the start and at the end of the pervaporation experiment is given in Table 1. 


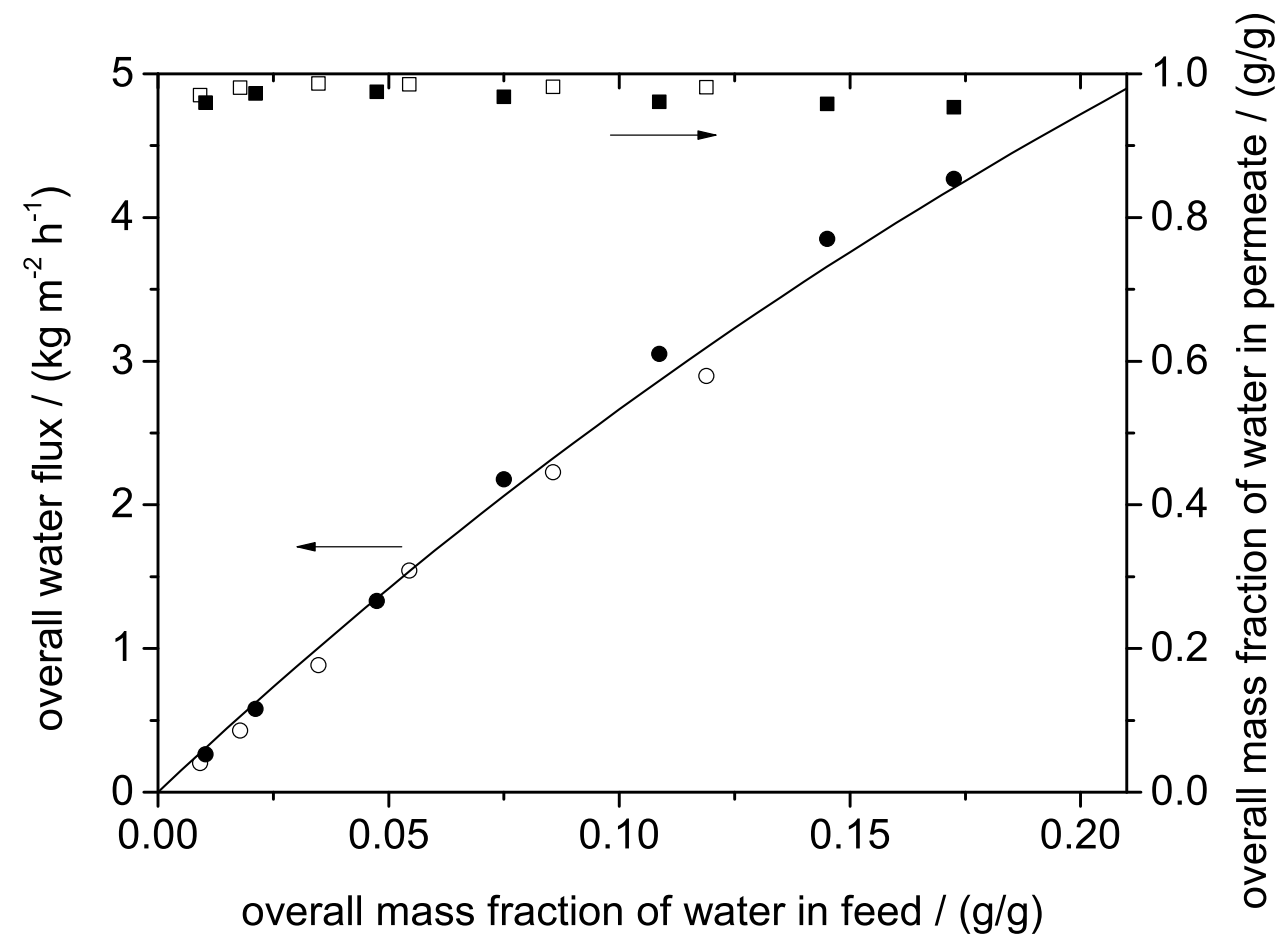

Figure 5: Experimental overall water fluxes $(\circ, \bullet)$ and overall mass fraction of water in the permeate $(\square, \boldsymbol{\square})$ using the polymeric membrane PERVAP 4100 for the pervaporation. Open symbols: New membrane. Filled symbols: repeat experiment with used membrane. The temperature is $353 \mathrm{~K}$, the permeate pressure is $2 \mathrm{mbar}$, and the volumetric feed flow rate is $80 \mathrm{l} / \mathrm{h}$. Solid lines: Correlation of the overall water flux using Eq. (2). The overall composition at the start and at the end of the pervaporation experiment is given in Table 1. 


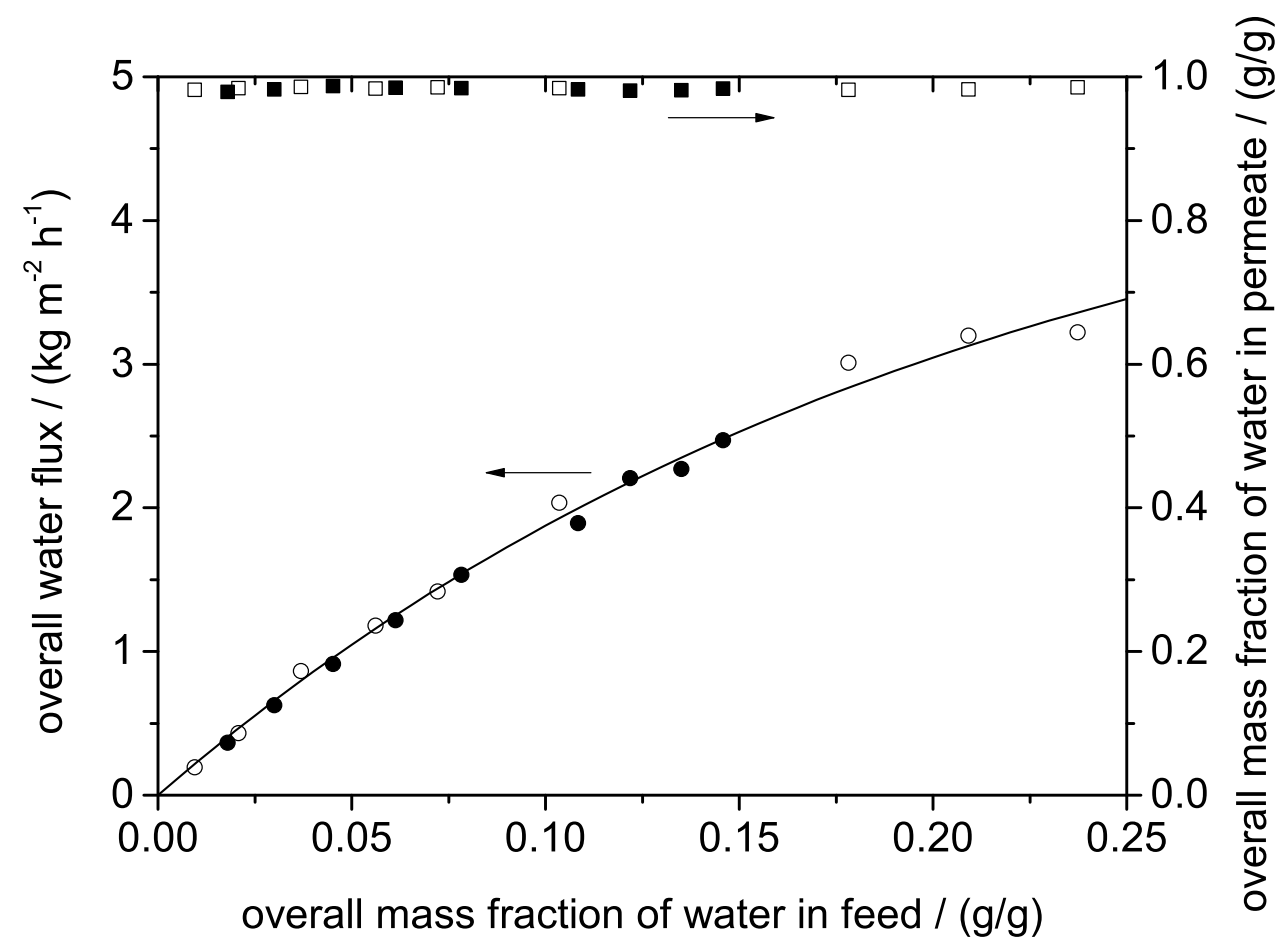

Figure 6: Experimental overall water fluxes $(\circ, \bullet)$ and overall mass fraction of water in the permeate $(\square, \boldsymbol{\square})$ using the polymeric membrane PERVAP 4101 for the pervaporation. Open symbols: New membrane. Filled symbols: repeat experiment with used membrane. The temperature is $353 \mathrm{~K}$, the permeate pressure is $2 \mathrm{mbar}$, and the volumetric feed flow rate is $80 \mathrm{l} / \mathrm{h}$. Solid lines: Correlation of the overall water flux using Eq. (2). The overall composition at the start and at the end of the pervaporation experiment is given in Table 1. 


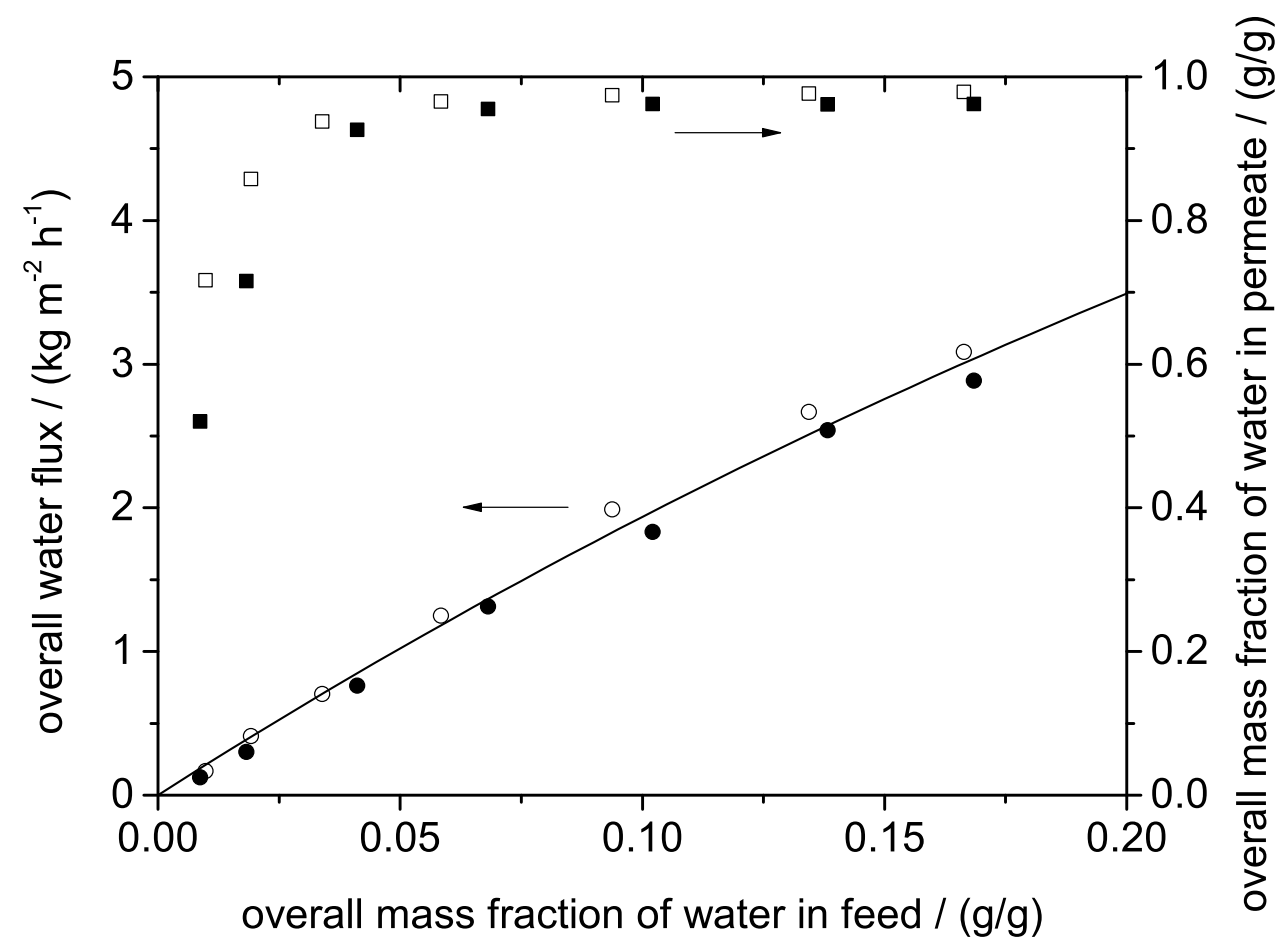

Figure 7: Experimental overall water fluxes $(\circ, \bullet)$ and overall mass fraction of water in the permeate $(\square, \boldsymbol{\square})$ using the polymeric membrane PERVAP 4102 for the pervaporation. Open symbols: New membrane. Filled symbols: repeat experiment with used membrane. The temperature is $353 \mathrm{~K}$, the permeate pressure is $2 \mathrm{mbar}$, and the volumetric feed flow rate is $80 \mathrm{l} / \mathrm{h}$. Solid lines: Correlation of the overall water flux using Eq. (2). The overall composition at the start and at the end of the pervaporation experiment is given in Table 1. 


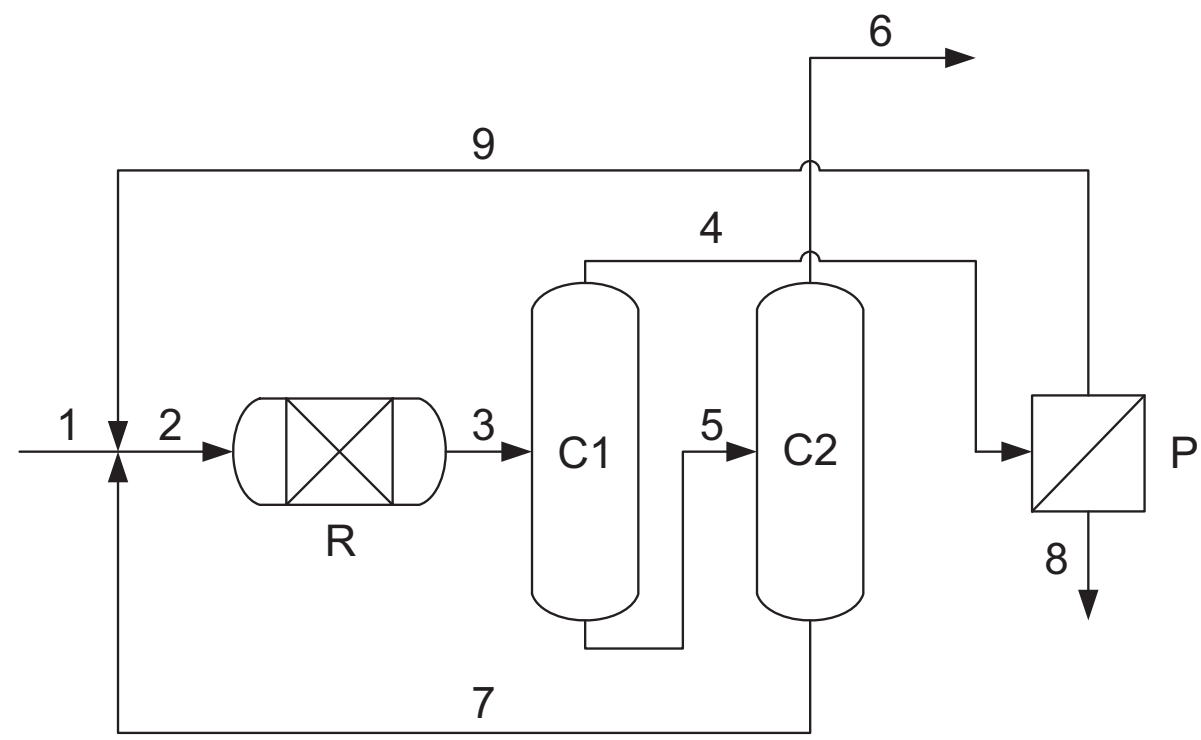

Figure 8: Flowsheet of the OME production process [22]. R: Reactor; C1, C2: Distillation columns; P: Pervaporation unit. 